RESEARCH

\title{
MYOCARDIAL INJURY AFTER NONCARDIAC SURGERY IN GERIATRIC PATIENTS
}

Turkish Journal of Geriatrics

DOI: $10.31086 /$ tigeri.2021.232

2021; 24(3): 351-358

- Döndü GENÇ MORALAR 1

- Bedih BALKAN ${ }^{1}$

CORRESPONDANCE

\section{${ }^{1}$ Döndü Genç MORALAR}

Health Sciences University, Gaziosmanpaşa

Education and Research Hospital, Anesthesia

and Reanimation Clinic, İstanbul, Turke

Phone: +905053737913

e-mail: dondugencm@gmail.com

Received: Apr 10, 2021

Accepted: Sep 03, 2021

${ }^{1}$ Health Sciences University, Gaziosmanpaşa Education and Research Hospital, Anesthesia and Reanimation Clinic, İstanbul, Turkey

2 Health Sciences University,Mehmet Akif Ersoy Education and Research Hospital, Anesthesia and Reanimation Clinic, Istanbul, Turkey

\section{Abstract}

Background: Myocardial injury after noncardiac surgery is an independent predictor of mortality in the postoperative period, and the risk is higher in geriatric patients than it is for other groups. However, this condition is thought to be underdiagnosed. To obtain a diagnosis, measuring high-sensitivity cardiac troponin is critical during postoperative monitoring. This study aimed to evaluate the presence of myocardial injury after noncardiac surgery occurring in geriatric patients during the perioperative period.

Methods: This study included 259 patients over 65 years of age. A peak high-sensitivity cardiac troponin value of $\geq 0.03 \mathrm{ng} / \mathrm{mL}$ was accepted as a diagnostic criterion for myocardial injury after noncardiac surgery. The patients were divided into two groups - those who were diagnosed with myocardial injury after noncardiac surgery (Group A) and those who were not (Group B). Incidence rates, 30-day mortality rates, hospital stay durations, levels of urgency, and comorbidities were compared between the two groups.

Results: The mortality rate in Group A (25\%) was significantly higher than that in Group B (5.8\%; $p<0.001)$. In addition, the hospital stay duration was significantly longer in Group A. Finally, the rates of diabetes, coronary artery disease, and chronic renal failure were significantly higher in Group A.

Conclusions: The results of our study indicated that the mortality rate and hospital stay duration were significantly higher in geriatric patients with myocardial injury after noncardiac surgery. We think that high-sensitivity cardiac troponin values should be routinely monitored in the postoperative period in patients over 65 years of age for timely treatment of myocardial injury.

Keywords: Postoperative Complications; Troponin; Mortality; Geriatrics. 


\section{INTRODUCTION}

After noncardiac surgery, major adverse cardiac events are leading causes of morbidity and mortality in patients (1). More than 200 million adults who undergo noncardiac surgery develop a myocardial injury each year, and this is estimated to result in 1 million deaths annually (2). Myocardial injury after noncardiac surgery (MINS) is a relatively new term for postoperative myocardial injury, and it is thought to be underdiagnosed.

Diagnosis of MINS is difficult because patients are unable to describe certain symptoms, such as angina pectoris and dyspnea, because of analgesia, sedation, and intubation, as well as because changes in electrocardiography (ECG) are nonspecific $(1,3-5)$. Therefore, assessing high-sensitivity cardiac troponin (hs-cTnT) is critical for detecting acute myocardial injury (6-11). MINS is diagnosed from postoperative hs-cTnT elevation in the presence or absence of clinical symptoms. It is seen in $8 \%-22 \%$ of adults who undergo noncardiac surgeries, and it is an independent predictor of 30-day and 1-year mortality $(7,12)$. Previous studies have investigated the role of hs-cTnT in perioperative myocardial ischemic events and have demonstrated the prognostic function of postoperative hs-cTnT elevation $(4,13)$.

In a prospective study of more than 15,065 patients who underwent noncardiac surgery, the patients were screened within the first 3 days postoperatively for troponin elevation and ischemic symptoms. Although troponin elevation was observed in $8 \%$ of the patients, myocardial ischemic findings were detected in only half of this group (7). In a PErioperative ISchemic Evaluation (POISE) study, $5.0 \%$ of patients had a perioperative myocardial infarction, $65.3 \%$ of patients did not experience ischemic symptoms and the 30-day mortality rate was $11.6 \%$ (4).

Performing perioperative troponin follow-up can play a potentially critical role in improving patient outcomes (2). For this reason, routine monitoring of cardiac troponin is recommended to identify patients at risk for early postoperative cardiovascular events (14). This new definition has been recommended as a guide for timely diagnosis and intervention (15). Although studies have investigated this topic, no specific study has paired the issue of MINS with geriatric patients. Moreover, geriatric patients have insufficient cardiovascular compensation and extra concomitant comorbidities compared with other patients. For these reasons, we examined myocardial damage in geriatric patients during the perioperative period. The primary outcome was a comparison of mortality rates in patients with MINS diagnoses. The secondary outcomes were troponin levels, hospital stay durations, operation durations, comorbidities and their associations with MINS, and the rates of MINS in emergency cases.

\section{METHODS}

This study received ethical approval from the Clinical Research Ethics Committee of Bakırköy Dr. Sadi Konuk Education and Research Hospital (decision no. 2018/02/29). The study was retrospective, and no written consent was attempted. We included 259 American Society of Anesthesiologists (ASA) Score 1-3 patients older than 65 years of age who had undergone operations at the Bakırköy Dr. Sadi Konuk Education and Research Hospital between January 1, 2017, and January 1, 2018. Patient data, including troponin values, were reviewed and collected retrospectively from the hospital's electronic database and death notification system, and their demographic data and accompanying diseases were recorded. The records were assessed, checked, and verified. The type, duration, and urgency of the operation were noted. Between January 1, 2017, and January 1, 2018, 1,180 patients underwent surgery at the Bakırköy Dr. Sadi Konuk Education and Research Hospital. We excluded patients with ASA 4 status who had undergone intracranial and cardiovascular surgery and patients with incomplete data.

Because myocardial injuries typically occurred 
within 3 days after the operation, hs-cTnT values were evaluated using the Elecsys 2010 Troponin $T$ hs STAT test (Roche Diagnostics) for the first 3 days postoperatively. A peak hs-cTnT level of $0.03 \mathrm{ng} / \mathrm{mL}$ or higher was accepted as a diagnostic criterion for MINS.

The patients were divided into two groupsthose diagnosed with MINS (Group A) and those who had no such diagnosis (Group B). The 30-day mortality rates, hospital stay durations, associations with comorbid diseases, and incidence rates of MINS in emergency cases were compared between the two groups.

\section{Statistical method}

Data are presented as mean \pm standard deviation or median (range). The normality of distribution was measured with the Kolmogorov-Smirnov test. The Mann-Whitney $U$ test was used to analyze the quantitative independent data, and the chi-square test or Fischer's exact test was used to analyze the qualitative independent data. SPSS v22.0 was used for all analyses.

\section{RESULTS}

This study included 259 geriatric patients (116 [44.8\%] women and 143 [55.2\%] men). The mean patient age was $74.12 \pm 7.3$ years. The mean age of the patients with MINS (Group A) was $76.1 \pm$ 7.7 years, whereas the mean age of the patients without a MINS diagnosis (Group B) was $72.8 \pm 6.8$ years. Thus, the mean age of Group $A$ was significantly higher $(p<0.05)$. The demographic data of the patients participating in the study are shown in Table 1.

The highest troponin levels of the included patients in the first 3 days postoperatively were considered. Patients with hs-cTnT $>0.03 \mathrm{ng} / \mathrm{mL}$ were diagnosed as having MINS

The mortality rate in Group A (25\%) was significantly higher than that in Group B $(5.8 \% ; p<0.05$; Table 2). The mortality rates according to age distribution are presented in Table 2. In addition, the hs-cTnT values were significantly different between the groups (Table 3).

The hospital stay duration in Group A was significantly higher than that in Group B ( $p<0.05$; Table 4).

Table 1. Summary of patients' demographic data

\begin{tabular}{|c|c|c|c|c|}
\hline \multirow{2}{*}{\multicolumn{2}{|c|}{$\begin{array}{c}\text { Mean } \pm \text { SD } \\
n(\%)\end{array}$}} & Group A & Group B & $p$ \\
\hline & & \multicolumn{2}{|c|}{$\begin{array}{c}\text { Mean } \pm \text { SD } \\
n(\%)\end{array}$} & \\
\hline \multirow{4}{*}{$\begin{array}{c}\text { Age groups } \\
\text { (years) }\end{array}$} & & $76.1 \pm 7.7$ & $72.8 \pm 6.8$ & $0.001^{a}$ \\
\hline & $65-74$ & 49 (47.1\%) & 105 (67.7\%) & \multirow{3}{*}{$0.001^{b}$} \\
\hline & $75-84$ & 35 (33.7\%) & 39 (25.2\%) & \\
\hline & $\geq 85$ & 20 (19.2\%) & $11(7.1 \%)$ & \\
\hline \multirow{2}{*}{ Gender } & Female & 52 (50.0\%) & 64 (41.3\%) & \multirow{2}{*}{$0.167^{b}$} \\
\hline & Male & 52 (50.0\%) & 91 (58.7\%) & \\
\hline
\end{tabular}

${ }^{a}$ Mann-Whitney $\mathrm{U}$ test, ${ }^{\mathrm{b}}$ Chi-square test or Fischer's test 
Table 2. Comparison of mortality rates between groups

\begin{tabular}{|c|c|c|c|c|c|c|}
\hline \multirow{2}{*}{$\begin{array}{c}\text { Age } \\
\text { (years) }\end{array}$} & \multirow{2}{*}{ Mortality } & \multicolumn{2}{|c|}{ Group A } & \multicolumn{2}{|c|}{ Group B } & \multirow{2}{*}{$p$} \\
\hline & & $n$ & $\%$ & $\mathrm{n}$ & $\%$ & \\
\hline \multirow{2}{*}{$\geq 65$} & Deceased & 26 & $25 \%$ & 9 & $5.8 \%$ & \multirow{2}{*}{$<0.001$} \\
\hline & Alive & 78 & $75 \%$ & 146 & $94.2 \%$ & \\
\hline \multirow{2}{*}{$65-74$} & Deceased & 10 & $20.4 \%$ & 5 & $4.8 \%$ & \multirow{2}{*}{0.003} \\
\hline & Alive & 39 & $79.5 \%$ & 100 & $95,2 \%$ & \\
\hline \multirow{2}{*}{$75-84$} & Deceased & 10 & $28.6 \%$ & 2 & $5.1 \%$ & \multirow{2}{*}{0.007} \\
\hline & Alive & 25 & $71.4 \%$ & 37 & $94.9 \%$ & \\
\hline \multirow{2}{*}{$\geq 85$} & Deceased & 6 & $30.0 \%$ & 2 & $18.2 \%$ & \multirow{2}{*}{0.394} \\
\hline & Alive & 14 & $70.0 \%$ & 9 & $81.8 \%$ & \\
\hline
\end{tabular}

Table 3. Comparison of troponin values between groups

\begin{tabular}{|c|c|c|c|c|}
\hline \multirow{2}{*}{} & & Deceased & Alive \\
\cline { 3 - 4 } & & Mean \pm SD & Mean \pm SD & \multirow{2}{*}{ P } \\
\hline \multirow{2}{*}{ Troponin value } & Group A & $0.282 \pm 0.502$ & $0.153 \pm 0.254$ & $<0.001$ \\
\cline { 2 - 5 } & Group B & $0.020 \pm 0.008$ & $0.012 \pm 0.008$ \\
\hline
\end{tabular}

The p-values were measured using the Chi-square test or Fischer's test.

Table 4. Comparison of length of hospital stay and operation duration between groups

\begin{tabular}{|c|c|c|c|c|c|c|c|}
\hline & \multicolumn{3}{|c|}{ Group A } & \multicolumn{3}{|c|}{ Group B } & \multirow{2}{*}{$p$} \\
\hline & Mean & SD & Median & Mean & SD & Median & \\
\hline $\begin{array}{l}\text { Length of hospital stay } \\
\text { (days) }\end{array}$ & 14.6 & 14.3 & 8.5 & 9.7 & 10 & 6.0 & 0.025 \\
\hline $\begin{array}{l}\text { Duration of the operation } \\
\text { (min) }\end{array}$ & 135 & 85.2 & 110.0 & 183.8 & 111.3 & 150.0 & 0.001 \\
\hline
\end{tabular}

The $p$-values were measured using the Mann-Whitney $U$ test. 
Moreover, the incidence rates of MINS were similar between the patients undergoing emergency surgery $(10.6 \%)$ and those undergoing elective surgery (5.8\%). Longer operation times did not increase the risk of MINS (Table 4). Rates of diabetes, coronary artery disease, and chronic renal failure were significantly higher in Group A patients ( $p<0.05$; Table 5).

\section{DISCUSSION}

Different mechanisms have been suggested for the development of MINS, including surgical stress, catecholamine release, and inflammatory reactions in the perioperative period (16). The physiological response to surgical stress, which lasts up to a few days after surgery, increases oxygen consumption; moreover, hypotension, anemia, hypoxia, and hypovolemia are common in the perioperative period, and these conditions reduce oxygen delivery. The imbalance between myocardial supply and oxygen demand can lead to MINS (3).

One study demonstrated that chronic catecholamine stimulation aggravates myocardial damage by provoking an inflammatory reaction and increasing myocardial apoptosis (17). If cardiac cellular damage is caused by trauma, ischemia, or any other factor, the cell becomes hyperactive, and intracellular contents spill into the extracellular space and the bloodstream. If the myocyte damage is sufficiently large, these compounds can be detected using biochemical assays. Detection of troponin in the plasma indicates heart injury. Thus, with hs-cTnT level monitoring, myocardial ischemia can be detected without myocardial necrosis; the value increases in proportion to the level of ischemia, appears rapidly in circulation after the onset of ischemia, and remains long enough for detection. It can be easily measured with high sensitivity and reasonable specificity (16).

In a study of 1,087 critically ill patients, $17.3 \%$ were diagnosed with MINS. The hs-cTnT levels increased in $59.0 \%$ of MINS-diagnosed patients immediately after surgery, $71.8 \%$ after $24 \mathrm{~h}$, and $24.5 \%$ after $48 \mathrm{~h}$. The authors suggested that the troponin level should be monitored for the first $48 \mathrm{~h}$ postoperatively (15). In our research, the highest troponin values seen in the first $72 \mathrm{~h}$ were obtained.

Table 5. Comparison of comorbidities according to group

\begin{tabular}{|c|c|c|c|c|c|}
\hline & Group A & & Group & & \multirow{2}{*}{$p$} \\
\hline & $n$ & $\%$ & $n$ & $\%$ & \\
\hline Hypertension & 24 & 23,1 & 26 & $16.8 \%$ & 0.208 \\
\hline Diabetes & 19 & $18.3 \%$ & 10 & $6.5 \%$ & 0.003 \\
\hline Coronary artery disease & 25 & $24 \%$ & 15 & $9.7 \%$ & 0.002 \\
\hline Arrhythmia & 25 & $24 \%$ & 23 & $14.8 \%$ & 0.062 \\
\hline Chronic kidney failure & 23 & $22,1 \%$ & 10 & $6,5 \%$ & $<0.001$ \\
\hline Cerebrovascular disease & 0 & $0.0 \%$ & 1 & $0.6 \%$ & 1.000 \\
\hline Respiratory system Diseases & 24 & 23.1 & 26 & $16.8 \%$ & 0.217 \\
\hline
\end{tabular}

The $p$-values were measured using the chi-square test or Fischer's test. 
In one study, the mortality rate was $16.9 \%$ among patients with peak $\mathrm{TnT} \geq 0.30 \mathrm{mg} / \mathrm{L}$ (18). Van Waes et al. (12) prospectively screened 3,224 patients aged $\geq 60$ years who underwent noncardiac surgery; postoperative myocardial injury was detected in 715 patients (22\%). In our study, the incidence of MINS increased with age in geriatric patients.

Inhibition of platelet function or perioperative suppression of sympathetic effects of the compensatory expansion of surgery has not been found to be beneficial in many clinical trials (19).

One study reported that myocardial injury developed in one of seven patients over 65 years of age who had coronary artery disease, peripheral arterial disease, or stroke (20). In our study, older age and accompanying diseases, such as coronary artery disease, increased the risk of MINS.

In a prospective multicenter study including 3,387 patients undergoing noncardiac surgery, Sabaté et al. (21) found that chronic renal failure was associated with major cardiac and cerebrovascular events. We also observed chronic renal failure more frequently in patients with MINS.

Few studies have evaluated the relationship between operation duration and MINS. Bae et al. (22) reported that the duration of surgery was associated with MINS. In contrast, our data indicated that the operation duration did not increase with the development of MINS; in fact, MINS was more commonly noted in operations of shorter durations.

Studies have demonstrated that emergency operations are independent risk factors for MINS. In these operations, there is not enough preoperative evaluation or preparation because of their urgent nature, intraoperative hypotension and arrhythmia are more common, and blood transfusions are more frequently needed (15). However, the incidence of MINS in our study was similar in emergency and elective cases.
MINS is a frequent complication after noncardiac surgery; it is found early in routine clinical screening, and it has been shown to be associated with shortand long-term mortality $(4,5,7,23)$. In our study, mortality and morbidity rates were significantly higher in patients over 65 years of age who were diagnosed with MINS compared with those who were not diagnosed with MINS. MINS was more common in patients with accompanying diabetes, coronary artery disease, and chronic renal failure.

Many studies have investigated the role of cardiac troponins in diagnosing perioperative myocardial ischemic events and shown the prognostic value of postoperative cardiac troponin elevation $(4,23)$. Different studies used different values, such as 0.1 $\mathrm{ng} / \mathrm{mL}(5,23)$ or $0.14 \mathrm{mg} / \mathrm{L}(20)$, to diagnose MINS. As a result, we think that hs-cTnT values should be routinely monitored postoperatively in patients over 65 years of age for early diagnosis and timely treatment. However, additional prospective studies are required on this topic.

\section{Limitations of the study}

There are some limitations associated with this study that should be mentioned. The study was retrospective, involved a single center study, and only included patients whose hs-cTnT values were available in the medical records. Prospective studies with a large number of patients and different surgical groups will overcome these limitations, providing clearer information on the topic.

Conflicts of Interest: The authors declare no conflicts of interest.

Funding: No funding was received for this study.

Running Head: MINS in Geriatric Patients 


\section{REFERENCES}

1. Fleisher LA, Fleischmann KE, Auerbach AD, et al. 2014 ACC/AHA guideline on perioperative cardiovascular evaluation and management of patients undergoing noncardiac surgery: a report of the American College of Cardiology/American Heart Association Task Force on Practice Guidelines. Circulation 2014;130(24):e278-333 (PMID: 25085961)

2. Khan J, Alonso-Coello P, Devereaux PJ. Myocardial injury after noncardiac surgery. Curr Opin Cardiol 2014;29(4):307-311 (PMID: 25029449)

3. Landesberg G, Beattie S, Mosseri M, et al. Perioperative myocardial infarction. Circulation 2009;119(22):2936-44 (PMID: 19506125)

4. Devereaux PJ, Xavier D, Pogue J, et al.; POISE (PeriOperative ISchemic Evaluation) Investigators. Characteristics and short-term prognosis of perioperative myocardial infarction in patients undergoing noncardiac surgery: a cohort study. Ann Intern Med 2011;154(8):523-8 (PMID: 21502650)

5. Devereaux PJ, Chan MT V, Alonso-Coello P, et al. Association between postoperative troponin levels and 30-day mortality among patients undergoing noncardiac surgery. JAMA 2012;307(24):2295-304 (PMID: 22706835)

6. Van Waes JA, Nathoe HM, de Graaff JC, et al.; Cardiac Health After Surgery (CHASE) Investigators. Myocardial injury after noncardiac surgery and its association with short-term mortality. Circulation 2013;127(23):2264-71 (PMID: 23667270)

7. Botto F, Alonso-Coello P, Chan MT, et al.; Vascular Events in Noncardiac Surgery Patients Cohort Evaluation (VISION) Writing Group, on behalf of the Vascular Events in Noncardiac Surgery Patients Cohort Evaluation (VISION) Investigators. Myocardial injury after noncardiac surgery: a large, international, prospective cohort study establishing diagnostic criteria, characteristics, predictors, and 30-day outcomes. Anesthesiology 2014;120(3):564-78 (PMID: 24534856)

8. Ekeloef S, Alamili M, Devereaux PJ, et al. Troponin elevations after non-cardiac, non-vascular surgery are predictive of major adverse cardiac events and mortality: a systematic review and meta-analysis. Br J Anaesth 2016;117(5):559-68 (PMID: 27799170)

9. Devereaux PJ, Biccard BM, Sigamani A, et al. Association of postoperative high-sensitivity troponin levels with myocardial injury and 30-day mortality among patients undergoing noncardiac surgery. JAMA 2017;317(16):1642-51 (PMID: 28444280)

10. Kristensen SD, Knuuti J, Saraste A, et al. 2014 ESC/ ESA guidelines on non-cardiac surgery: cardiovascular assessment and management: The Joint Task Force on non-cardiac surgery: cardiovascular assessment and management of the European Society of Cardiology (ESC) and the European Society of Anaesth. Eur Heart J 2014;35(35):2383-431 (PMID: 25086026)

11. Thygesen K, Alpert JS, Jaffe AS, et al. Joint ESC/ ACCF/AHA/WHF Task Force for Universal Definition of Myocardial Infarction; Authors/Task Force Members Chairpersons; Biomarker Subcommittee; ECG Subcommittee; Imaging Subcommittee; Classification Subcommittee; Intervention Subcommittee; Trials \& Registries; ESC Committee for Practice Guidelines (CPG); Document Reviewers. Third universal definition of myocardial infarction. J Am Coll Cardiol 2012;60(16):1581-98 (PMID: 22958960)

12. Van Waes JA, Grobben RB, Nathoe HM, et al. Oneyear mortality, causes of death, and cardiac interventions in patients with postoperative myocardial injury. Anesth Analg 2016;123(1):29-37 (PMID: 27111647)

13. Devereaux PJ, Goldman L, Cook DJ, et al. Perioperative cardiac events in patients undergoing noncardiac surgery: a review of the magnitude of the problem, the pathophysiology of the events and methods to estimate and communicate risk. CMAJ 2005;173(6):627-34 (PMID: 16157727)

14. Thygesen K, Alpert JS, Jaffe AS, et al. Joint ESC/ ACCF/AHA/WHF task force for the universal definition of myocardial infarction. Third universal definition of myocardial infarction. Circulation 2012;126(16):2020-35 (PMID: 22923432)

15. Zhao XJ. Zhu FX, Li S, et al. Acute kidney injury is an independent risk factor for myocardial injury after noncardiac surgery in critical patients. J Crit Care 2017;39:225-31 (PMID: 28202201)

16. Sun JZ. Maquire D. How to prevent perioperative myocardial injury: the conundrum continues. Am Heart J 2007;154(6):1021-8 (PMID: 18035070)

17. Hu A, Jiao X, Gao E, et al. Chronic beta-adrenergic receptor stimulation induces cardiac apoptosis and aggravates myocardial ischemia/reperfusion injury by provoking inducible nitric-oxide synthasemediated nitrative stress. J Pharmacol Exp Ther 2006;318(2):469-75 (PMID: 16574780) 
18. Iglesias PP, Ruano SD, Álvarez-García J. Myocardial injury after noncardiac surgery. Rev Esp Cardiol 2014;67(10):794-6 (PMID: 25205649)

19. Devereaux PJ, Mrkobrada M, Sessler DI, et al. Aspirin in patients undergoing noncardiac surgery. $\mathrm{N}$ Engl J Med, 2014;370(16):1494-503 (PMID: 24679062)

20. Puelacher C, Lurati Buse G, Seeberger D, et al. BASEL-PMI Investigators. Perioperative Myocardial Injury After Noncardiac Surgery: Incidence, Mortality, and Characterization. Circulation, 2018:20;137(12):1221-32 (PMID: 29203498)

21. Sabaté S, Mases A, Guilera N, et al. Incidence and predictors of major perioperative adverse cardiac and cerebrovascular events in noncardiac surgery. $\mathrm{Br}$ J Anaesth 2011;107(6):879-90 (PMID: 21890661)

22. Bae MH, Lee JH, Yang DH, et al. Usefulness of surgical parameters as predictors of postoperative cardiac events in patients undergoing non-cardiac surgery. Circ J 2014;78:718-23. (PMID: 24351662)

23. Landesberg G, Shatz $\vee$, Akopnik I, et al. Association of cardiac troponin, CK-MB, and postoperative myocardial ischemia with long-term survival after major vascular surgery. J Am Coll Cardiol 2003;42(9):154754 (PMID: 14607436) 